\title{
Bond Performance of Carbon Fiber-Reinforced Polymer Bar with Dual Functions of Reinforcement and Cathodic Protection for Reinforced Concrete Structures
}

\author{
Yingwu Zhou, Lili Sui, Feng Xing $(\mathbb{D}$, Xiaoxu Huang, Yaowei Zheng, and Debo Zhao \\ Guangdong Provincial Key Laboratory of Durability for Marine Civil Engineering, Shenzhen University, Shenzhen 518060, China \\ Correspondence should be addressed to Debo Zhao; debozhao@163.com
}

Received 7 November 2019; Accepted 18 December 2019; Published 25 January 2020

Guest Editor: Tianyu Xie

Copyright ( 2020 Yingwu Zhou et al. This is an open access article distributed under the Creative Commons Attribution License, which permits unrestricted use, distribution, and reproduction in any medium, provided the original work is properly cited.

\begin{abstract}
The dual function of a carbon fiber-reinforced polymer (CFRP) bar working as reinforcement and impressed current cathodic protection (ICCP) anode for reinforced concrete structures has been proposed and researched in this paper. The ICCP tests with different current densities and polarization durations were first conducted for the concrete with high chloride content. After the ICCP application, pull out tests were then performed to investigate the bond behaviors of CFRP bars. Experimental results have shown the effectiveness of the new-type ICCP system with the CFRP bar as the anode on corrosion protection. The ICCP system provided electrons to the steel bar continuously and brought the potential of the steel bar down to the immunity region. Under the anodic polarization with a large current density of $100 \mathrm{~mA} / \mathrm{m}^{2}$, the CFRP bar-concrete interface presented acidification and the chemical adhesion on the interface was decreased significantly. However, for cases in the experiment, the ICCP application had an insignificant influence on the ultimate bond strength.
\end{abstract}

\section{Introduction}

The durability of reinforced concrete (RC) structures (Figure 1(a)) can be significantly deteriorated due to the impact of rebar corrosion [1-3]. In order to overcome the corrosion issue, research has been carried out in recent decades to incorporate corrosion-resistant materials, such as fiber-reinforced polymer (FRP), into concrete structures $[4,5]$. Replacing traditional steel bars with FRP bars can effectively inhibit corrosion and improve the durability of concrete structures [6, 7]. However, due to the low elastic modulus and brittle behavior of some FRP materials, problems exist in FRP-reinforced concrete (FRPRC) structures (Figure 1(b)), such as the high deformability, the lack of ductility, and large crack widths [8-11]. Thus, the design of FRPRC components is generally dominated by the serviceability limit state requirements, such as the crack width and deformation limits. Moreover, the bond performance between FRP bars and matrix become crucial because it influences the crack width and spacing of FRPRC components significantly $[12,13]$. The performances of concrete structures can be improved significantly by utilizing a combination of FRP and steel reinforcements [14-18]. In a hybrid FRP-steel reinforced concrete (hybrid FRPRC) beam (Figure 1(c)), the corrosion-resistant FRP bars are usually placed at the lower layer of the tensile zone, while the corrodible steel bars are placed at the upper layer of the tensile zone far from the environmental aggressive agents, mainly chloride ion. By optimizing the design, the hybrid reinforced concrete structures can be featured with large rigidity, high ductility and ultimate bearing capacity, and good corrosion resistance and durability.

Besides, the steel corrosion in RC structures can be inhibited with electrochemical technologies. The impressed current cathodic protection (ICCP) technique, as illustrated in Figure 2, is widely accepted as an effective approach to prevent corrosion of steel reinforcements $[19,20]$. By applying a current to a steel bar with an external power supply, the steel bar becomes a cathode and its potential is adjusted down to suppress the migration of electrons generated by the 


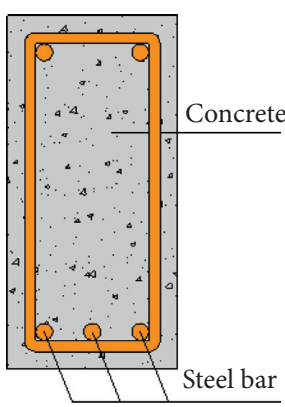

(a)

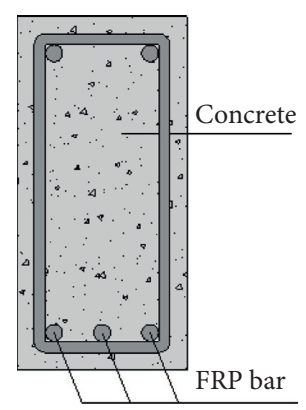

(b)

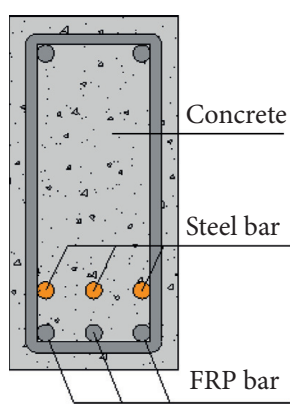

(c)

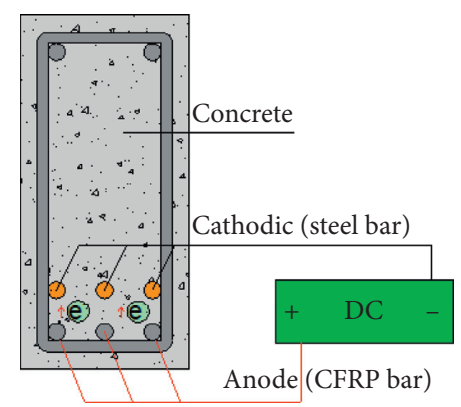

(d)

FIGURE 1: Illustrations of (a) RC structure; (b) FRPRC structure; (c) hybrid FRPRC structure; (d) hybrid FRPRC structure with ICCP-CB technique.

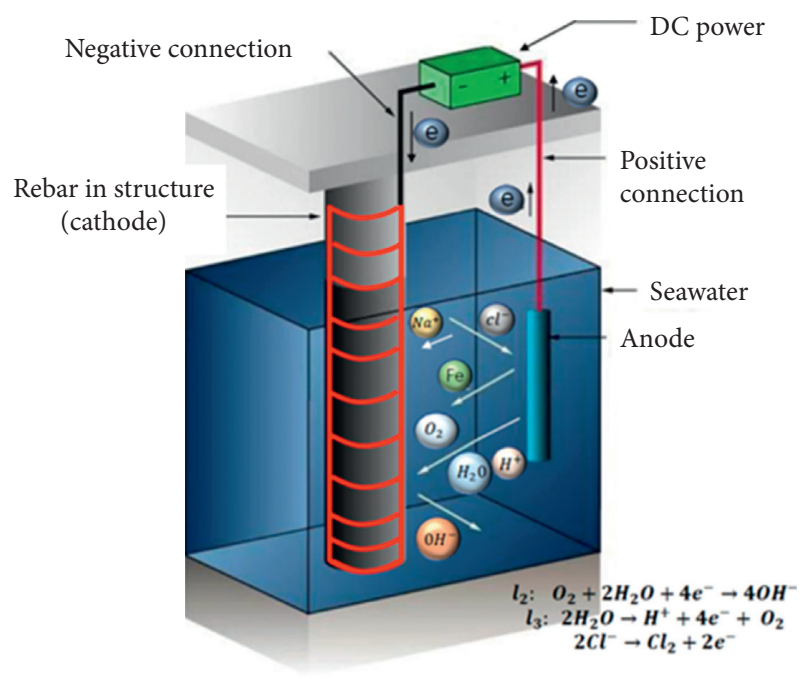

Figure 2: Schematic diagram of the ICCP technique.

corrosion. The failure of the ICCP system is mainly due to the deterioration of the anode material or bond interface between the anode and concrete [21, 22]. Therefore, intensive research has focused on the development of anode with better performance characteristics, such as lower bond deficiency and acidification. Recent research shows that CFRP is a promising anode material because of its good conductivity and electrochemical stability. Lee-Orantes et al. [23] conducted an experimental investigation on a reinforced concrete cathodic protection system with CFRP anodes, and no apparent degradation of carbon composites and conductive resins was observed. The ICCP tests of RC beams conducted by Gadve et al. [24] demonstrated that using FRP wraparounds as an anode effectively retarded the corrosion of steel, and the loss of bond between steel and concrete can be avoided by selecting the appropriate protection current density. Moreover, considering its excellent mechanical properties, FRP can be applied to RC structures with dual functions of corrosion protection and structural strengthening, and in this case, the bond degradation between FRP and concrete during the ICCP process plays a crucial role in structural performances. Lambert et al. [25] used CFRP fabric for both flexural strengthening of precorroded reinforced concrete beams and a dual functional capacity as an ICCP anode. The flexural testing after a period of ICCP operation showed that FRP debonding induced a $13.5 \%$ decrease in the ultimate strength of RC beams incorporating dual function CFRP anodes, compared with corresponding beams with CFRP strengthening only. Van Nguyen et al. [26] investigated the dual function of a CFRP rod working as the near-surface mounted (NSM) strengthening and ICCP anode, and in this system, the bonding between the CFRP rod anode and concrete interface was improved by using a combination of geopolymer and epoxy resin. Experimental results showed that the high current density did not affect the bonding of the CFRP rod significantly.

The ICCP technique can be applied to the hybrid FRPRC structures by using CFRP bars (CB) embedded in the structures as the anode. The resulting structure (Figure 1(d)) is expected to have excellent mechanical performances as well as corrosion resistance, which is especially suitable for chloride-rich environments such as coastal and offshore areas. To evaluate the feasibility of the ICCP-CB technique, the electrochemical properties and bond performances of CFRP bar anode were investigated using a simulated ICCP system in this paper. In the simulated ICCP system, current density and duration were varied to determine appropriate protection parameters. After that, pull out tests were performed on specimens to study the short-term bond behaviors of the CFRP bar-concrete interface in the anode region after high-current cathodic protection.

\section{Experimental Program}

2.1. Material Properties. CFRP bars and steel bars used in the experiment both have a diameter of $12 \mathrm{~mm}$, and the mechanical properties are shown in Table 1. The ribbed CFRP bar is depictured in Figure 3. In order to exert a better conductivity, CFRP bars were polished to remove the surface resin before the electrochemical test. In order to simulate the chloride-rich environment, sea-sand $\left(\mathrm{Cl}^{-}\right.$content: $\left.0.05 \%\right)$ and seawater $\left(\mathrm{Cl}^{-}\right.$content: $\left.2.00 \times 10^{4} \mathrm{mg} / \mathrm{L}\right)$ were used to mix the concrete. The natural sea-sand and seawater were obtained from the offshore area of Fuyong wharf, Shenzhen, China. The detailed chemical compositions of natural 
TABLE 1: Mechanical properties of CFRP bars and steel bars.

\begin{tabular}{lcccccc}
\hline Bar type & Diameter $(\mathrm{mm})$ & Initial stiffness $(\mathrm{GPa})$ & Yield strain $(\%)$ & Yield strength $(\mathrm{MPa})$ & Ultimate strain (\%) & Ultimate stress $(\mathrm{MPa})$ \\
\hline CFRP & 12 & 125 & - & - & - & 788 \\
Steel & 12 & 201.37 & 0.23 & 433.21 & 0.48 & 582.52 \\
\hline
\end{tabular}

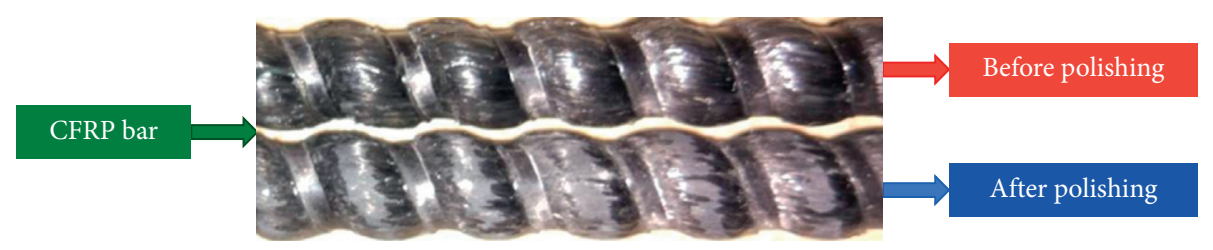

FIgURE 3: Shape of the CFRP bar.

seawater are listed in Table 2. Ordinary Portland cement (P.O 42.5 R) was used for the cement, and gravels with a diameter between $12 \mathrm{~mm} 20 \mathrm{~mm}$ were used for the coarse aggregate. The mix proportion of concrete in weight was 1 : $0.49: 1.58: 2.81$ (cement: water: sand:gravel). The compressive strengths of concrete at 28 days and before pull out tests were $42.4 \mathrm{MPa}$ and $54.2 \mathrm{MPa}$, respectively, which were determined with cubic specimens with a side length of $100 \mathrm{~mm}$.

2.2. Specimen Design. A total of 15 specimens were prepared for the ICCP test and pull out test, which were divided into five groups according to different experimental variables, and each group had three identical specimens. The shape of the specimen is illustrated in Figure 4. The specimens was designed according to the Chinese standard GB 50152-92 [27], and the specimens dimensions were adjusted a little to fit the existing molds in the laboratory. The concrete matrix of each specimen was a cubic with a length of $100 \mathrm{~mm}$. A CFRP bar with a length of $450 \mathrm{~mm}$ was laid through the centerline of the specimen. The CFRP bar was extended from the specimen left surface for $300 \mathrm{~mm}$ to facilitate applying load and installing extensometers in the pull out test. Meanwhile, a $50 \mathrm{~mm}$ CFRP bar was extended beyond the right surface of the cylinder for the connection of anode in the ICCP test and the installation of extensometers in the pull out test. In the $100 \mathrm{~mm}$ midsection, the bonding area was designed as $48 \mathrm{~mm}$ and the left $52 \mathrm{~mm}$ section was set to be nonbonding areas, where Teflon tape was used to separate the concrete from the CFRP bar. The nonbonding area was designed primarily to avoid local failure of the ends resulting from stress concentration. A steel bar with $98 \mathrm{~mm}$ length was arranged right above the CFRP bar, with a center to center distance of $25 \mathrm{~mm}$. The steel bar was embedded in the concrete with a length of $48 \mathrm{~mm}$, and the extended $50 \mathrm{~mm}$ section was for the connection of cathode in the ICCP system.

The experimental variables in the ICCP test include current density and polarization duration. According to NACE SP0290-2007 [28], current densities of 5, 20, 50, and $100 \mathrm{~mA} / \mathrm{m}^{2}$ were applied on specimens in 4 groups, respectively, while the other group was set as a reference group and did not undergo the ICCP test. In each group, two specimens were tested for polarization duration of 4 months, while the other one had a polarization duration of 6 months. The detailed experimental parameters of specimens are listed in Table 3. The specimen identification is defined as I-current density-polarization duration. For example, a specimen named I-5-4M denotes that the current density and polarization duration in the ICCP test are $5 \mathrm{~mA} / \mathrm{m}^{2}$ and 4 months, respectively. Besides, " $R$ " denotes replicated specimens and "RF" represents specimens in the reference group.

2.3. ICCP Test. ICCP tests begun after the specimens were cured in the laboratory environment for 60 days. Before ICCP application, both the steel bar and the CFRP bar extended outside the concrete cubic were polished to ensure a good conductivity at the cathode and anode connection. The schematic view and real picture of the ICCP test system are shown in Figure 5. During the ICCP test, the potential of the steel bar was measured by $\mathrm{Ag} / \mathrm{AgCl}$ reference electrodes and a digital voltmeter (DVM). Three kinds of potential were recorded: on-potential, instant-off potential, and depolarization potential measured 4 hours after pausing the cathodic protection system. According to the ASTM C876 standard, the relationship between the rebar corrosion potential and the probability of corrosion is as follows: for potentials (ref. electrode: $\mathrm{Ag} / \mathrm{AgCl}$ ) larger than $-119 \mathrm{mV}$, the probability that no steel corrosion occurs is larger than $90 \%$; For potentials (ref. electrode: $\mathrm{Ag} / \mathrm{AgCl}$ ) smaller than $-269 \mathrm{mV}$, the probability that steel corrosion occurs is larger than 90\%; for potentials falling between these limits, the corrosion activity of the reinforcing steel is uncertain. Moreover, after the ICCP system lasts for 120 days, linear polarization resistance of the steel bar was measured and the corresponding corrosion current density was obtained by the Stern-Geary relationship [29] to evaluate the corrosion state of the steel bar.

2.4. Uniaxial Pull Out Test. After ICCP operation, pull out tests were conducted on specimens to investigate the bond performance of CFRP bars after galvanostatic anodic polarization. Considering the low shear strength of CFRP bars, an $80 \mathrm{~mm}$ long aluminum sleeve was adhered outside the loading end of the bar to prevent it from being damaged by the chuck of the testing machine, as shown in Figure 6. 
TABLE 2: Chemical compositions of nature seawater (in $\mathrm{mg} / \mathrm{L}$ ).

\begin{tabular}{|c|c|c|c|c|c|c|c|c|}
\hline $\mathrm{Na}^{+}$ & $\mathrm{K}^{+}$ & $\mathrm{Ca}$ & $\mathrm{Mg}$ & $\mathrm{F}^{-}$ & $\mathrm{Cl}^{-}$ & $\mathrm{Br}^{-}$ & $\mathrm{SO}_{4}{ }^{2-}$ & $\mathrm{CO}_{3}{ }^{2-}$ \\
\hline 395.0 & 422.5 & $1.24 \times 10^{4}$ & $1.00 \times 10^{3}$ & 5.14 & $2.00 \times 10^{4}$ & 48.55 & $1.82 \times 10^{3}$ & 7.54 \\
\hline
\end{tabular}

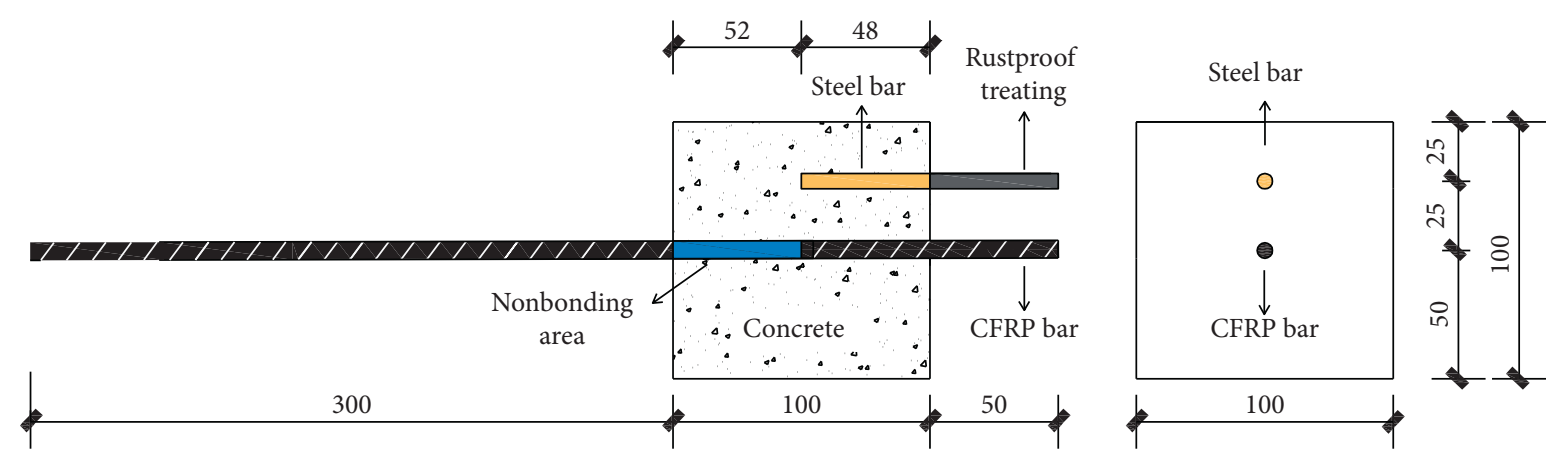

FIGURE 4: Schematic of the unidirectional pull out specimen (unit: $\mathrm{mm}$ ).

TABLE 3: Experimental parameters of specimens.

\begin{tabular}{lcc}
\hline Specimen no. & Current density $\left(\mathrm{mA} / \mathrm{m}^{2}\right)$ & $\begin{array}{c}\text { Polarization } \\
\text { duration (day) }\end{array}$ \\
\hline I-0-RF-1 & 0 & 0 \\
I-0-RF-2 & 0 & 0 \\
I-0-RF-3 & 0 & 0 \\
I-5-4M & 5 & 120 \\
I-5-4M-R & 5 & 120 \\
I-5-6M & 5 & 180 \\
I-20-4M & 20 & 120 \\
I-20-4M-R & 20 & 120 \\
I-20-6M & 20 & 180 \\
I-50-4M & 50 & 120 \\
I-50-4M-R & 50 & 120 \\
I-50-6M & 50 & 180 \\
I-100-4M & 100 & 120 \\
I-100-4M-R & 100 & 120 \\
I-100-6M & 100 & 180 \\
\hline
\end{tabular}

The pull out test setup is shown in Figure 7. The pull out tests scheme followed the Chinese standard GB 50152-92 [27]. The tests were conducted with a servo-hydraulic testing machine with a capacity of $300 \mathrm{kN}$. Extensometers were installed on the loading end and free end of the specimen to measure the slips, and a load cell attached at the bottom of counterforce frame recorded the pull out force. The specimens were tested under the displacement-control mode with a loading rate of $0.05 \mathrm{~mm} / \mathrm{min}$. A data acquisition system was used to collect the test data with a sampling frequency of $5 \mathrm{~Hz}$. The average bond stress $\tau$ is defined as

$$
\tau=\frac{F}{\pi d l_{b}}
$$

where $F$ is the applied load and $d$ and $l_{b}$ are the rebar diameter and bond length, respectively.

Moreover, after the pull out test, phenolphthalein solution was sprayed on the bonded area of the split concrete matrix to investigate the acidification condition of the CFRP bar-concrete interface.

\section{Test Results and Discussion}

3.1. ICCP Test. During the ICCP test, the depolarization potential of the steel bar was monitored since the specimens were cured for 28 days till the pull out test begun. The measured potential, as shown in Figure 8, can be used as an index for reinforcement corrosion monitoring. Based on the evaluation criterion described in Section 2.3, during the natural corrosion stage between 28 and 70 days of curing, the corrosion potentials of all specimens were between $-269 \mathrm{mV} \sim-119 \mathrm{mV}$, indicating an uncertain probability of steel corrosion. After the ICCP test begun, all specimens with ICCP application had corrosion potentials more positive than $-119 \mathrm{mV}$, indicating that the steel passivation appeared and the probability of corrosion is less than $10 \%$. However, for specimens in the reference group without ICCP application, the corrosion potentials continued to decline and were lower than $-269 \mathrm{mV}$ after 98 days of curing, which means that the corrosion probability is larger than $90 \%$. The monitoring results showed the effectiveness of the ICCP technique: the corrosion process of reinforcing steel with ICCP protection was inhibited, while steel corrosion continued to develop for specimens without ICCP protection. The measured on-potential histories of specimens during the ICCP test are shown in Figure 9. After the ICCP application, the on-potentials at different current densities stabilized in a certain range and the curves dropped slightly with time increasing. The on-potential became more negative as current density increases.

The measured linear polarization resistance and corresponding corrosion current density of the steel bar at 120 days of ICCP application are listed in Table 4. The results of the polarization resistance measurements show that the specimens without ICCP protection were at a corrosion stage of a high probability, while those with ICCP protection were at a corrosion stage of a low probability. The results of the linear polarization resistance measurement further demonstrate the feasibility and effectiveness of the ICCP protection system with CFRP bar as the anode. 


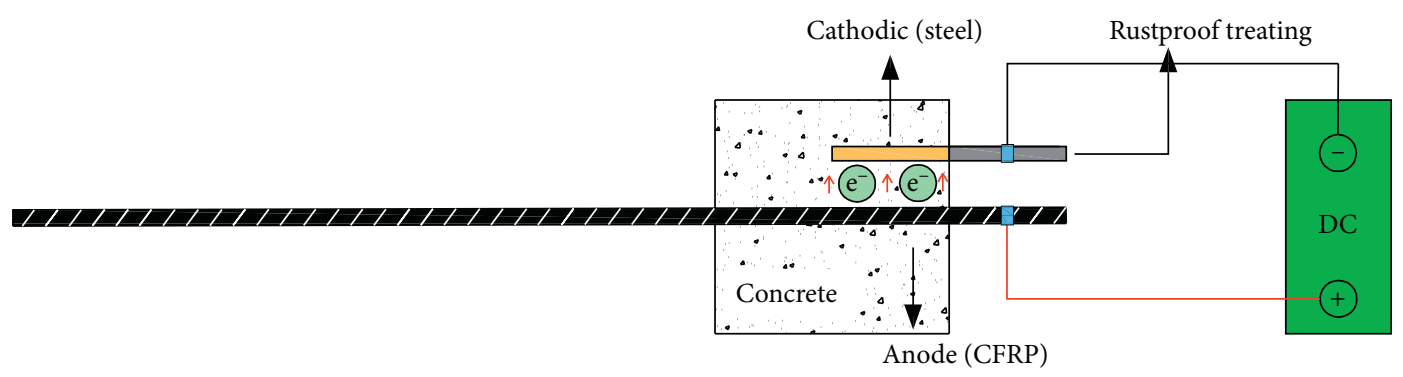

(a)

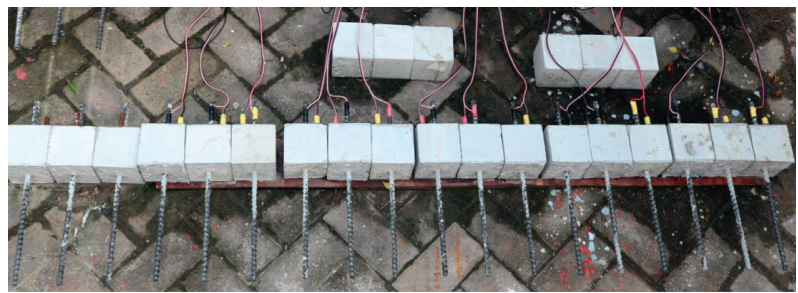

(b)

Figure 5: Test setup for ICCP system. (a) Schematic view. (b) Real picture.

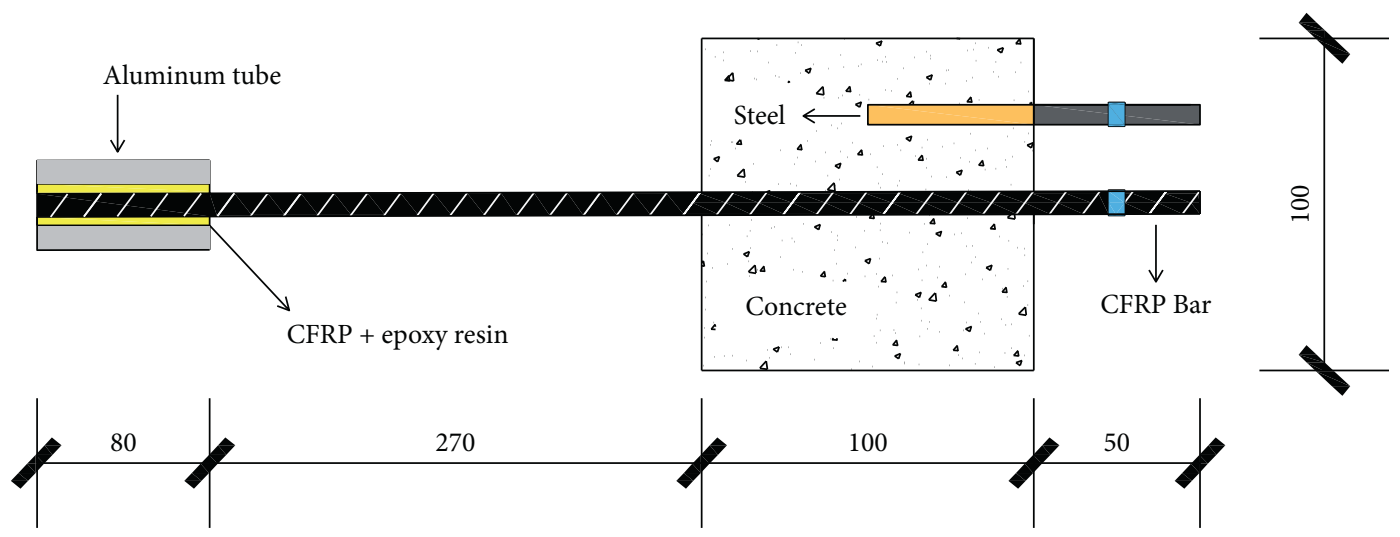

(a)

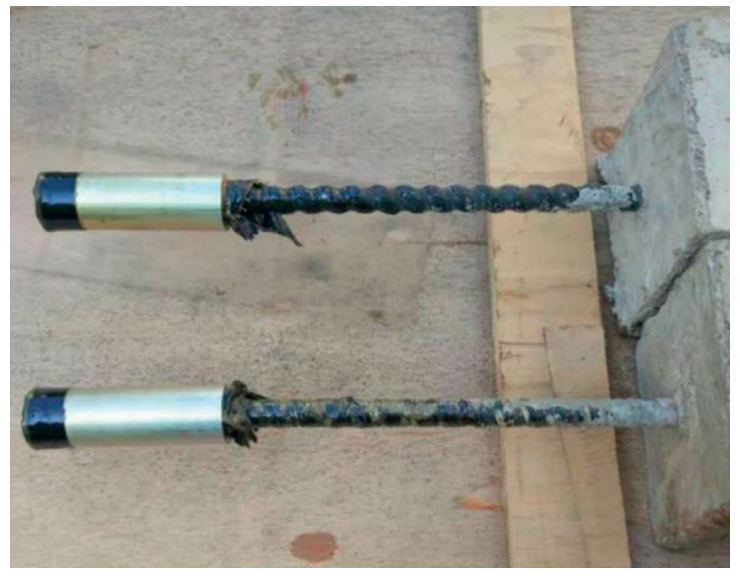

(b)

Figure 6: Schematic of the loading end reinforcement. (a) Schematic diagram (unit: mm). (b) Real picture.

\subsection{Pull Out Test}

3.2.1. Failure Mode. The overall failure mode of all specimens was splitting failure, as shown in Figure 10. During the pull out process, radical cracks first emerged at the free end of the specimen and then propagated toward the side surfaces, eventually splitting the concrete matrix into two or three parts. The indentations caused by CFRP bar ribs were 


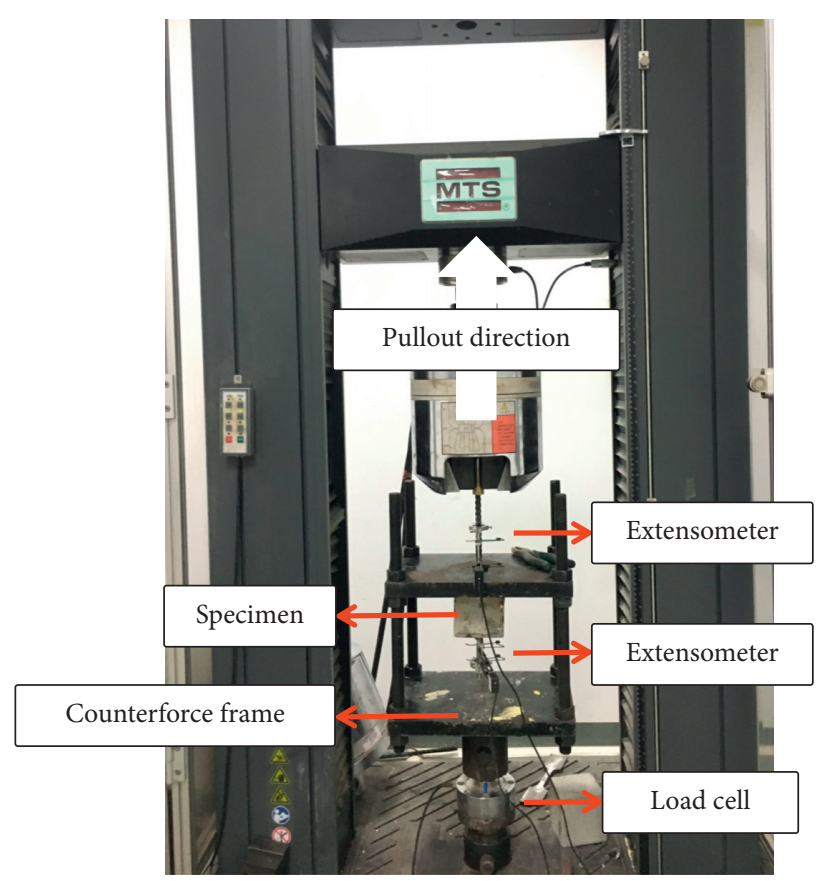

Figure 7: Pull out test setup.



FIGURE 8: Depolarization potential histories of steel bar during the ICCP tests.

clearly observed on the concrete matrix. The occurrence of splitting failure is caused by a large rib height of the CFRP bar and a relatively small concrete cover thickness. During the pull out process, the inclined ribs of the CFRP bar produced a high radical expansive stress on the concrete matrix, which exceeded the tensile strength of the concrete, leading to the radical cracks and eventually splitting of the matrix.
The local failure modes of the CFRP bar-concrete interface are shown in Figures 11 and 12. For specimens with different ICCP current densities, various failure patterns were observed on the CFRP bar-concrete interface. For I-0RF specimens, the rib indentations had a close color with the surrounding concrete, and textures created by the surface of the CFRP bar were clearly observed on the concrete interface. The yellow resin adhered to the surface of the CFRP 




FIgURE 9: On-potential histories of steel bar during the ICCP tests.

TABLE 4: Results of the polarization resistance measurements at 120 days of ICCP application.

\begin{tabular}{|c|c|c|c|c|}
\hline Specimen No. & $\begin{array}{l}\text { ICCP Current density } \\
\left(\mathrm{mA} / \mathrm{m}^{2}\right)\end{array}$ & $\begin{array}{c}\text { Linear polarization resistance } \\
(\mathrm{kOhms})\end{array}$ & $\begin{array}{l}\text { Corrosion current density } \\
\left(\mu \mathrm{A} / \mathrm{cm}^{2}\right)\end{array}$ & Corrosion stage \\
\hline I-0-RF & 0 & 0.367 & 1.28 & High \\
\hline I-5-4M & 5 & 3.409 & 0.13 & Low \\
\hline I-20-4M & 20 & 0.963 & 0.48 & Low \\
\hline I- $50-4 \mathrm{M}$ & 50 & 3.884 & 0.12 & Low \\
\hline $\mathrm{I}-100-4 \mathrm{M}$ & 100 & 3.279 & 0.14 & Low \\
\hline
\end{tabular}



(a)
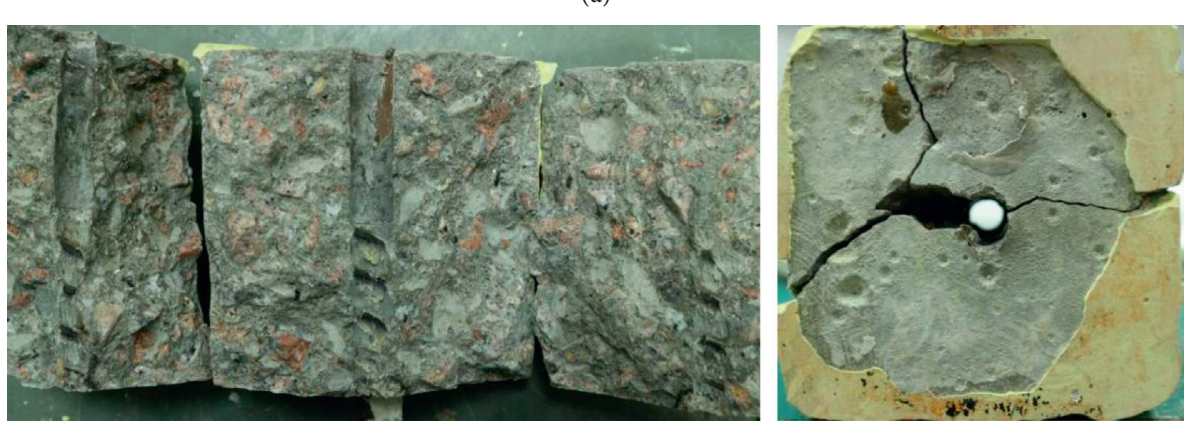

(b)

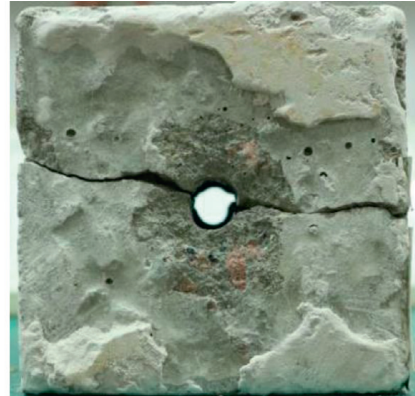

Figure 10: Overall bond failure patterns. (a) I-50-4M. (b) I-50-4M-R. 



FIGURE 11: Local failure patterns of concrete in the bonded area.

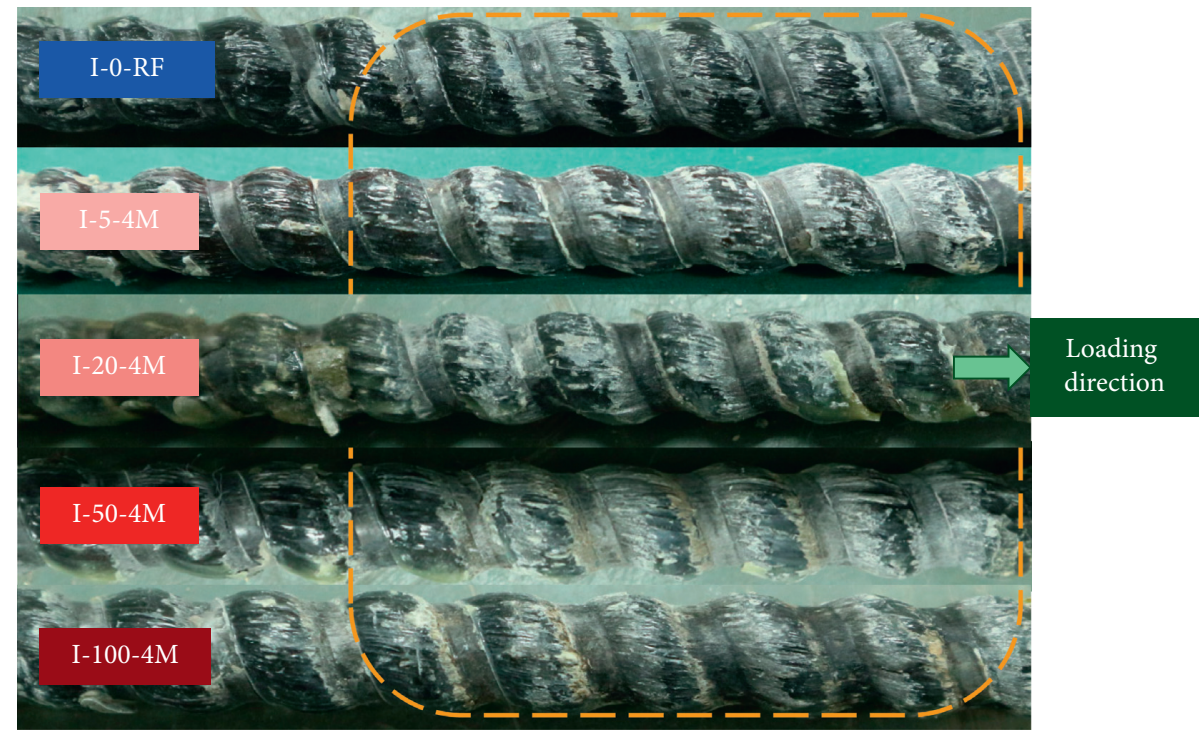

Figure 12: Local failure patterns of CFRP bar in the bonded area.

bar can be observed in some indentations, which coincides with the local failure pattern of CFRP bar: the ribs of CFRP bar were obviously scratched by the concrete matrix. I-5-4M specimens had a similar local failure pattern with I-0-RF specimens, except that the surface of the CFRP bar underwent more severe scraping. For I-20-4M specimens, the color of the rib indentations on concrete changed to be brown. The specimens in I-50-4M and I-100-4M groups had a deeper color of the rib indentation, and substances with light yellow color were observed on the surface of the CFRP bar, which should be chemical reactions of resins in CFRP bar under galvanostatic anodic polarization. The CFRP fibers on the rebar surface peeled off to some extent and adhered to the rib indentations of the concrete matrix. Generally, with the ICCP current density increased, the chemical reaction accelerated and the degradation of the CFRP bar-concrete interface caused by anodic polarization became more pronounced. Based on the experimental observations, it can be concluded that ICCP application with a current density of $5 \mathrm{~mA} / \mathrm{m}^{2}$ did not induce noticeable 

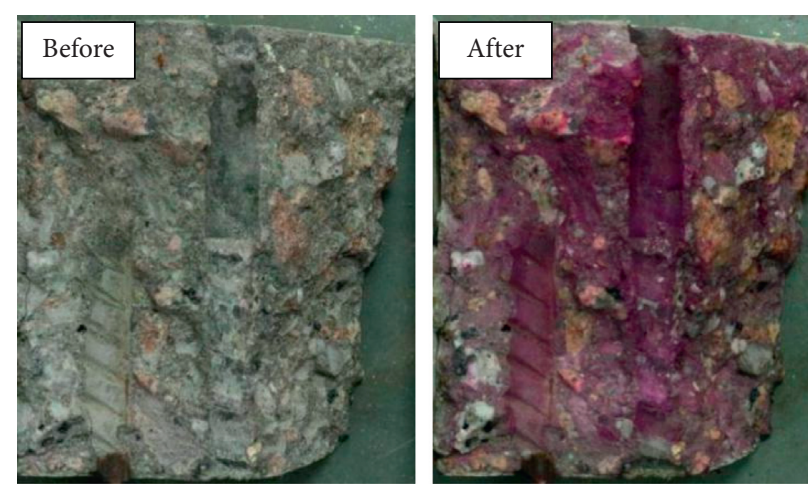

(a)
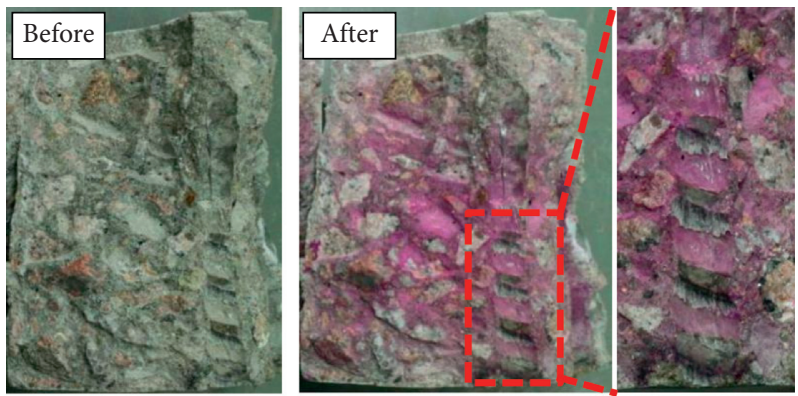

(c)

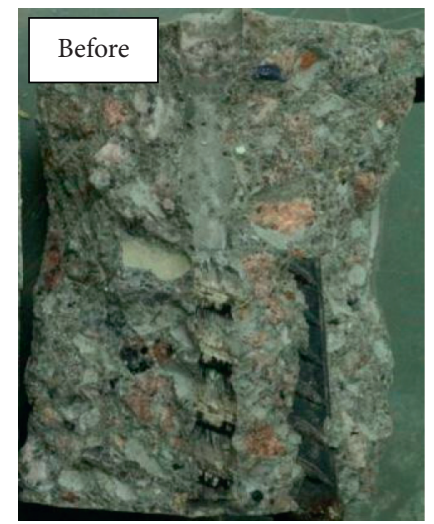

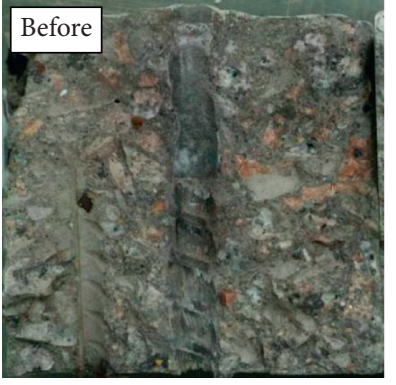



(b)
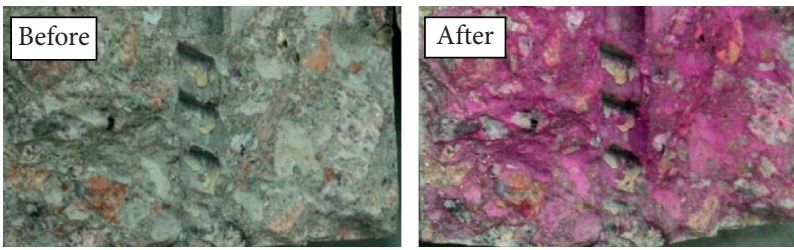

(d)

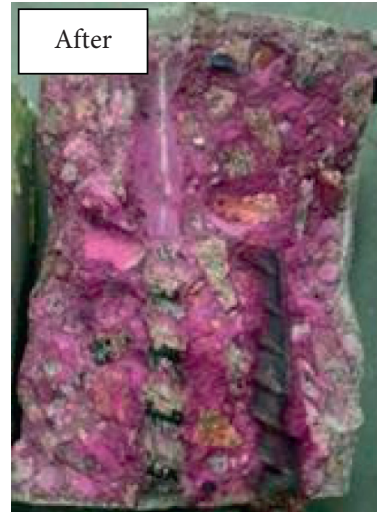

(e)

FIGURE 13: Real pictures of bonded areas before and after spraying phenolphthalein solution. (a) I-0-RF. (b) I-5-4M. (c) I-20-4M. (d) I-50-4M. (e) I-100-4M.

changes to the CFRP bar-concrete interface and that with $20 \mathrm{~mA} / \mathrm{m}^{2}$ had a little influence on the interface. However, ICCP applications with current densities of $50 \mathrm{~mA} / \mathrm{m}^{2}$ and $100 \mathrm{~mA} / \mathrm{m}^{2}$ deteriorated the CFRP bar-concrete interface significantly.

\subsubsection{Detection of Acidification of CFRP Bar-Concrete} Interface. Figure 13 shows real pictures of bonded areas before and after spraying phenolphthalein solution. For specimens with ICCP current densities of 0 and $5 \mathrm{~mA} / \mathrm{m}^{2}$, the bonded area appeared as red, indicating no acidification occurred on the CFRP bar-concrete interface. For specimens with ICCP current densities of 20,50, and $100 \mathrm{~mA} / \mathrm{m}^{2}$, the depressed areas of the rebar indentations appeared in red, while the color has not changed in the raised areas of the rebar indentations, indicating that the interface in this area was acidified. The acidification of the interface is mainly due to the oxygen-evolution and chlorine-evolution reactions under the electric field, as shown in equations (2) and (3). The generated $\mathrm{Cl}_{2}$ further reacts with $\mathrm{H}_{2} \mathrm{O}$ to form $\mathrm{HClO}$ and $\mathrm{HCl}$, as shown in equation (4). The hydrogen ions produced by these reactions are dissolved in the pore liquid on the interface, leading to the acidification of the interface:

$$
\begin{aligned}
2 \mathrm{H}_{2} \mathrm{O} & \longrightarrow \mathrm{O}_{2}+2 \mathrm{H}^{+}+4 \mathrm{e}^{-} \\
2 \mathrm{Cl}^{-} & \longrightarrow \mathrm{Cl}_{2}+2 \mathrm{e}^{-} \\
\mathrm{Cl}_{2}+\mathrm{H}_{2} \mathrm{O} & \longrightarrow \mathrm{HClO}+\mathrm{HCL}
\end{aligned}
$$






(a)

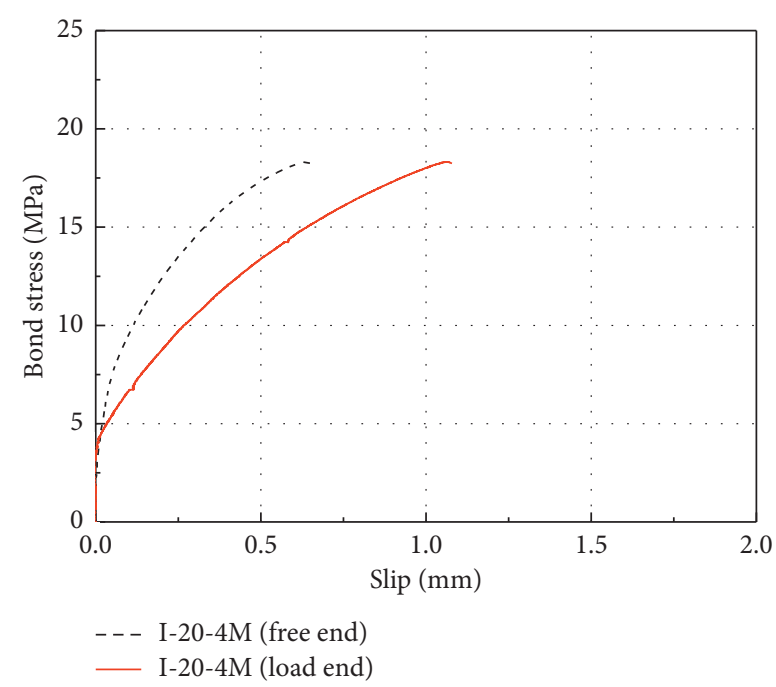

(b)

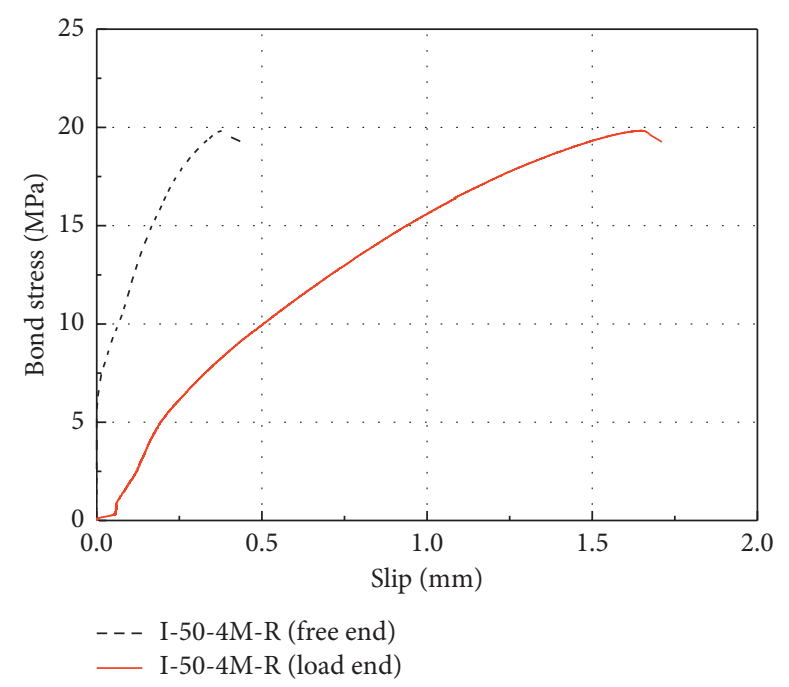

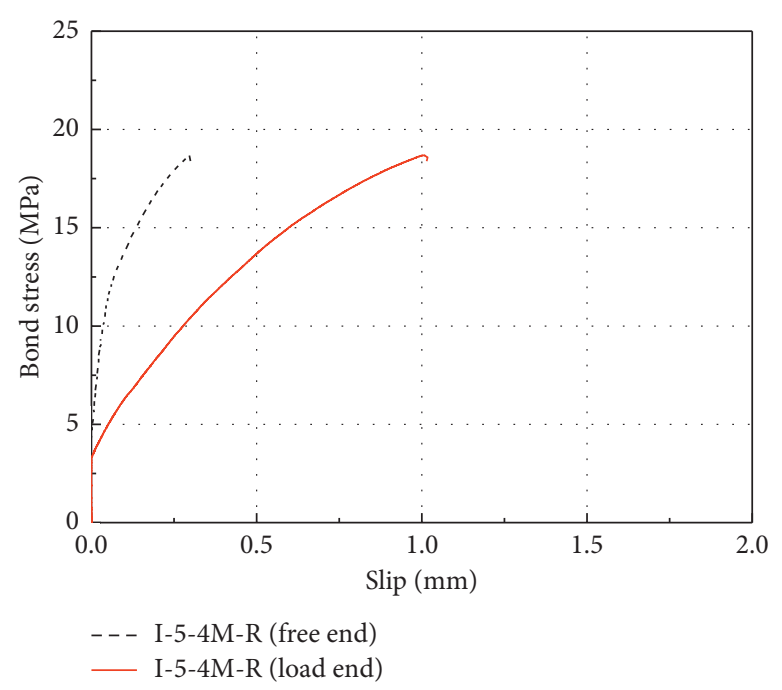
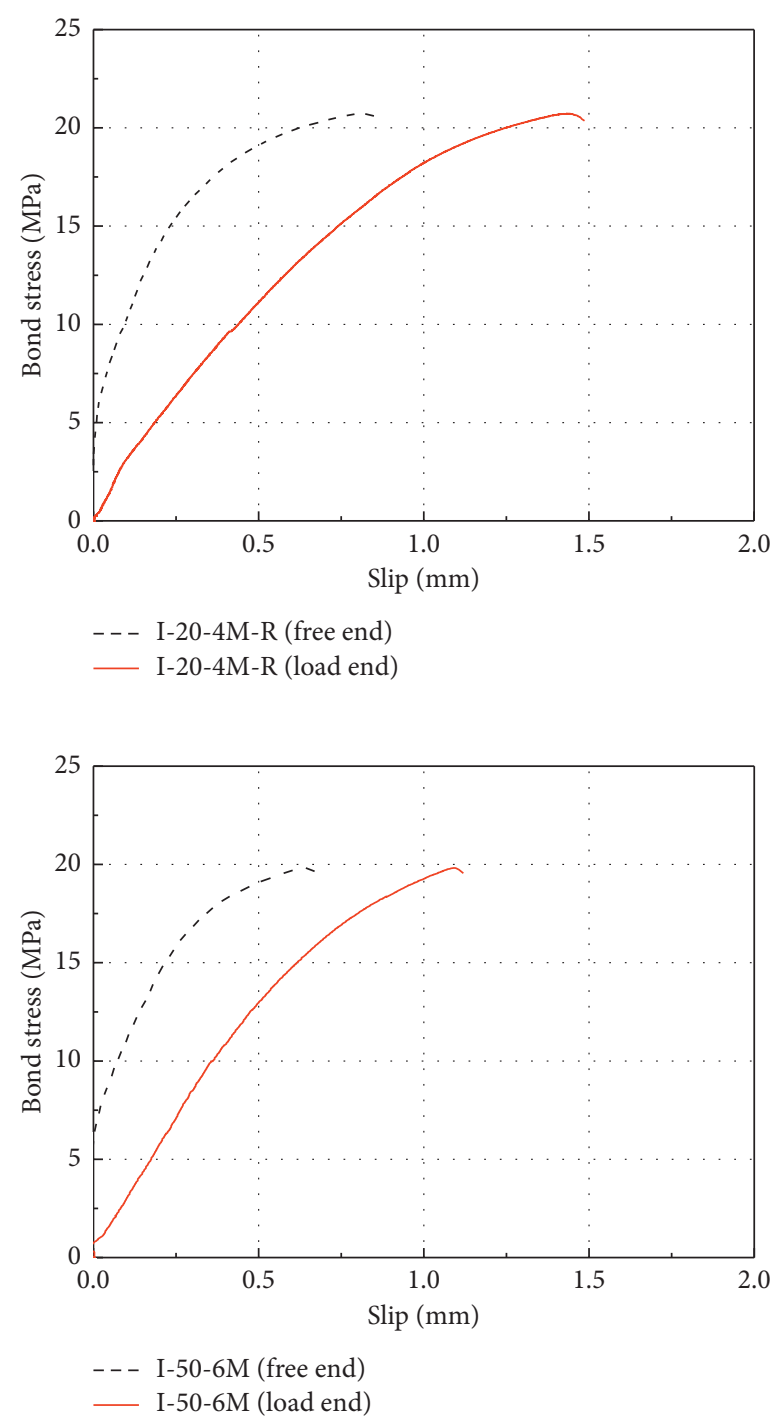

(c)

Figure 14: Continued. 


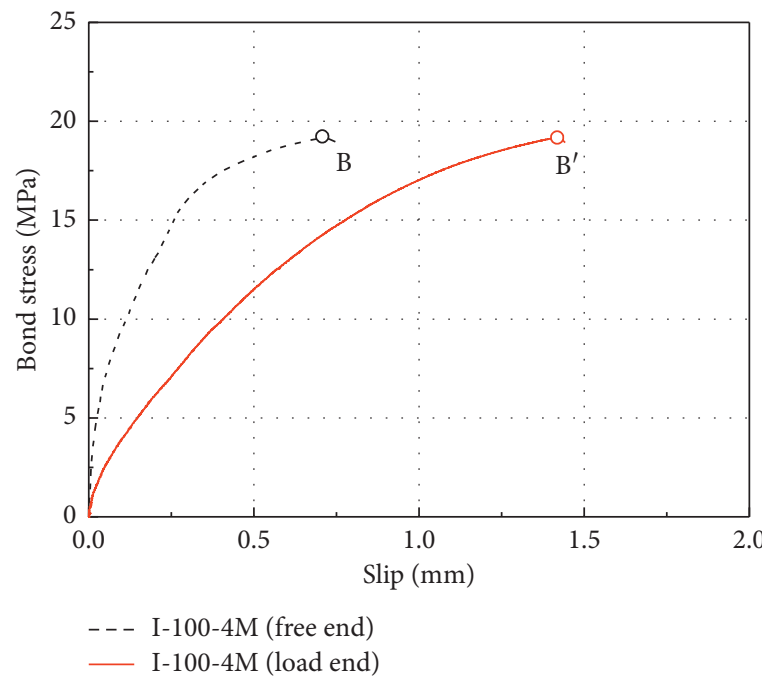

(d)

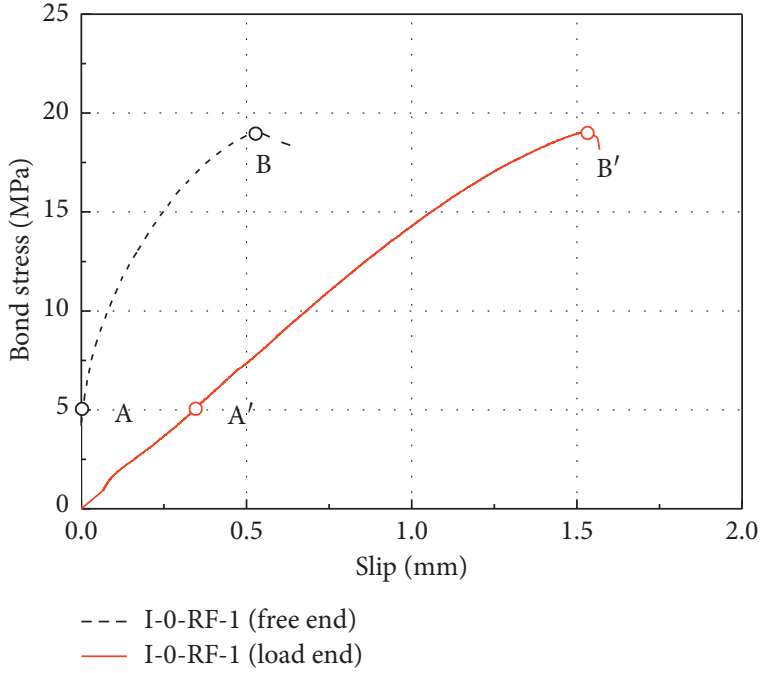

(e)

Figure 14: Typical bond-slip curves. (a) I-5. (b) I-20. (c) I-50. (d) I-100. (e) I-0.

TABle 5: Summary of pull out test results.

\begin{tabular}{llll}
\hline Specimen no. & $\tau_{\max }(\mathrm{MPa})$ & Average $\tau_{\max }(\mathrm{MPa})$ & $s_{\text {fmax }}(\mathrm{mm})$ \\
\hline I-0-RF-1 & 19.03 & & 0.68 \\
I-0-RF-2 & 17.13 & 18.96 & 0.33 \\
I-0-RF-3 & 20.73 & & 0.74 \\
I-5-4M & 21.98 & 20.33 & 0.71 \\
I-5-4M-R & 18.68 & 20.67 & 0.32 \\
I-5-6M & 20.67 & 19.53 & 0.35 \\
I-20-4M & 18.32 & - & 0.65 \\
I-20-4M-R & 20.73 & 18.9 & 0.88 \\
I-20-6M & a $^{-17.96}$ & 190 & - \\
I-50-4M & 17.96 & 19.55 & 0.44 \\
I-50-4M-R & 19.84 & 18.68 & 0.44 \\
I-50-6M & 19.55 & 17.48 & 0.68 \\
I-100-4M & 19.19 & & 0.75 \\
I-100-4M-R & 18.17 & & 0.49 \\
I-100-6M & 17.48 & & 0.39
\end{tabular}

${ }^{a}$ Data not measured.

3.2.3. Bond-Slip Curves. The measured bond-slip curves are shown in Figure 14. Characteristic values of bond-slip curves are summarized in Table 5, where $\tau_{\max }$ denotes the maximum bond stress and $s_{\text {fmax }}$ denotes the slip at free end corresponding to $\tau_{\max }$. Table 5 indicates that there is an obvious scattering for the test results of specimens in the same group, which is mainly caused by the deviation of the concrete tensile strength. Therefore, the average $\tau_{\max }$ is adopted as an index to evaluate the influence of ICCP test parameters on the bond performances. It can be seen from Table 5 that an increase in the ICCP current density results in a slight decrease of the average $\tau_{\max }$, while the polarization duration did not show an obvious influence on the average of $\tau_{\max }$ due to the relatively short duration of all the ICCP tests.

Figure 15 compares bond stress-free end slip curves at different ICCP current densities. For the specimen with a large ICCP current density of $100 \mathrm{~mA} / \mathrm{m}^{2}$, the free end slip

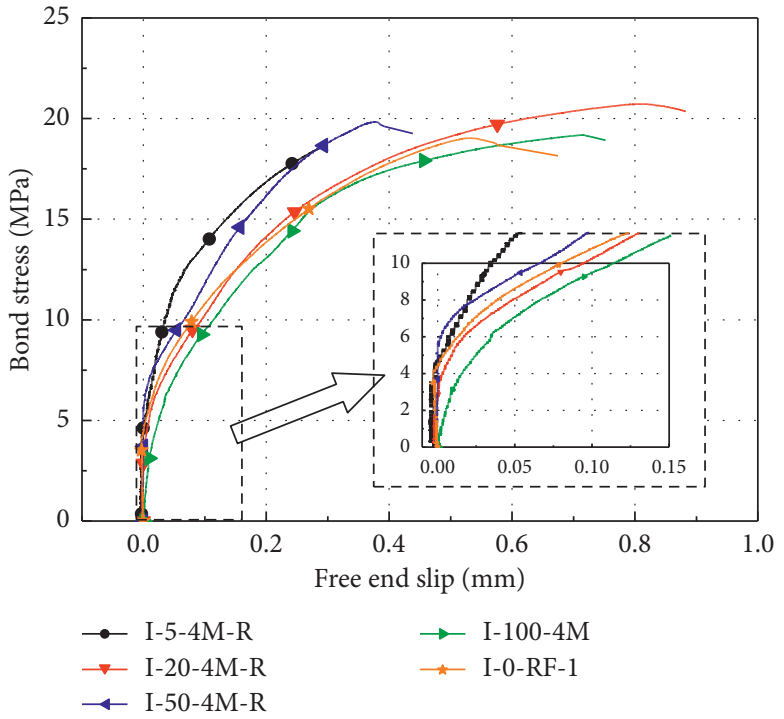

Figure 15: Bond-slip curves at different ICCP current densities.

emerged at the beginning of the loading. However, for other specimens, the free end began to slip at bond stress around $5 \mathrm{MPa}$. This phenomenon indicates that a large ICCP current density can change the bond mechanisms of the FRP barconcrete interface.

\subsubsection{Analysis of Bond Mechanisms of CFRP Bar-Concrete} Interface after Anodic Polarization. The bond stress between a ribbed bar and concrete is composed of the following parts: (1) chemical adhesion; (2) interlocking of the ribs against the concrete; (3) interface friction induced by circumference confinement of concrete cylinder [30]. For specimens without ICCP protection, the shift progress of three bond mechanisms at different stages of the bond-slip curve is schematically shown in Figure 16. In the initial stage of the 


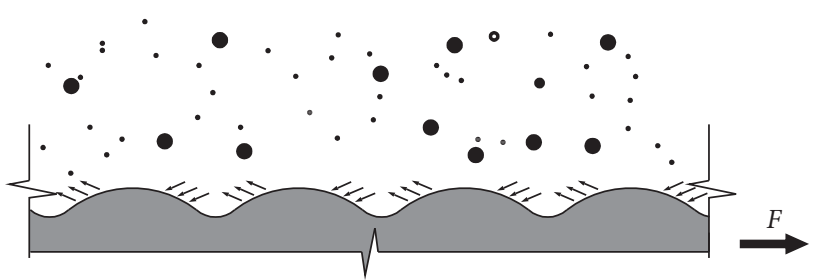

$\mathrm{O}-\mathrm{A}$



FIGURE 16: Illustration of bond mechanisms at different stages of the bond-slip curve.

pull out process (O-A stage in Figure 14(e)), the chemical adhesion plays a major role. In this stage, there was no slip at the free end and the slip at the loading end was contributed by the elastic deformation of the concrete matrix, resulting in an elastic bond behavior with large stiffness on the bondslip curve. With the load continuing to increase, the chemical adhesion interface was broken and the bond was gradually governed by the interlocking of the rebar ribs and the concrete matrix and interface friction. In this stage, the concrete expanded in the radial direction and cracked under the extrusion of inclined ribs, and the outer layer resin was scratched by hard concrete matrix. This nonlinear damage progress led to a nonlinear segment with a decreasing slope of the bond-slip curve (A-B stage in Figure 14(e)). At the peak load (Point B), the radical cracks propagated through the concrete cover, splitting the matrix cylinder into several parts and causing a sudden drop in the bond stress.

However, for specimens with ICCP application of a large current density, the CFRP bar-concrete interface underwent severe anodic polarization, which changed the bond behavior. Figure 14(d) shows that the O-A stage was absent in the bond-slip curve, and the free end of the CFRP bar slipped at the beginning of the loading. Considering that the O-A stage is mainly governed by the chemical adhesive force, it is reasonable to deduce that the anodic polarization of the ICCP test deteriorated the cementation interface and broke the chemical adhesion between CFRP bar and concrete. Therefore, in the pull out test, the bond-slip curve entered into the A-B stage controlled by the interlocking action and interface friction directly, and the following bond behavior was similar to that of specimens without ICCP application.

\section{Conclusion}

In this paper, the ICCP technique was applied to the hybrid CFRP-steel reinforced concrete structures with the CFRP bar as the anode material and reinforcement. To evaluate the effectiveness of the ICCP system on corrosion protection, the potential of steel bar was monitored during the ICCP test and the linear polarization resistance of steel bar was measured after the ICCP system ran for 120 days. After the ICCP application, pull out tests were conducted to investigate the bond performance of the CFRP bar-concrete interface under anodic polarization. Based on the experimental observation and analysis, the following conclusions can be drawn:

(1) ICCP-CB technique can effectively prevent the steel bar from corrosion for the hybrid CFRP-steel reinforce concrete structure. The ICCP system provided electrons to the steel bar continuously and brought the potential of the steel bar down to the immunity region. The measured linear polarization resistance of the steel bar also showed that the corrosion rate of steel bar under ICCP-CB protection was significantly lower than that without ICCP-CB protection.

(2) The CFRP bar-concrete interface presented acidification under anodic polarization, and the level of acidification increased as the ICCP current density increased. Furthermore, interfacial acidification concentrated in the raised areas of rebar indentations.

(3) The bond stress of the CFRP bar-concrete interface is mainly contributed by the chemical adhesion, the interface friction, and the interlocking action between rebar ribs and concrete matrix. The measured bond-slip curves show that the ICCP system with a large current density of $100 \mathrm{~mA} / \mathrm{m}^{2}$ reduced the chemical adhesion significantly, leading to the earlier slip for the free end of the CFRP bar.

(4) The CFRP bar in the ICCP-CB system has a reliable bond performance in short-term. An increase in ICCP current density resulted in a slight decrease in the bond strength, while the polarization duration had an insignificant influence on the bond strength.

\section{Data Availability}

All data used to support the findings of this study are available from the corresponding author upon request.

\section{Conflicts of Interest}

The authors declare that they have no conflicts of interest.

\section{Acknowledgments}

The work described in this paper was financially supported by the National Natural Science Foundation of China (Grants nos. 51878414, 51808345, and 51978412). The authors are grateful for each one of these contributions.

\section{References}

[1] A. Poursaee, Corrosion of Steel in Concrete Structures, Woodhead Publishing, Sawston, UK, 2016.

[2] K. Bhargava, A. K. Ghosh, Y. Mori, and S. Ramanujam, "Model for cover cracking due to rebar corrosion in RC 
structures," Engineering Structures, vol. 28, no. 8, pp. 10931109, 2006.

[3] C. Jiang, Y.-F. Wu, and M.-J. Dai, "Degradation of steel-toconcrete bond due to corrosion," Construction and Building Materials, vol. 158, pp. 1073-1080, 2018.

[4] H. Fang, Y. Bai, W. Liu, Y. Qi, and J. Wang, "Connections and structural applications of fibre reinforced polymer composites for civil infrastructure in aggressive environments," Composites Part B: Engineering, vol. 164, pp. 129-143, 2019.

[5] B. Hu, Y. Zhou, F. Xing, L. Sui, and M. Luo, "Experimental and theoretical investigation on the hybrid CFRP-ECC flexural strengthening of RC beams with corroded longitudinal reinforcement," Engineering Structures, vol. 200, Article ID 109717, 2019.

[6] Z. Wang, X.-L. Zhao, G. Xian et al., "Long-term durability of basalt- and glass-fibre reinforced polymer (BFRP/GFRP) bars in seawater and sea sand concrete environment," Construction \& Building Materials, vol. 139, pp. 467-489, 2017.

[7] S. El-Gamal, B. Benmokrane, E. El-Salakawy, P. Cousin, and A. Wiseman, "Durability and structural performance of carbon fibre reinforced polymer-reinforced concrete parking garage slabs," Canadian Journal of Civil Engineering, vol. 36, no. 4, pp. 617-627, 2009.

[8] H. A. Abdalla, "Evaluation of deflection in concrete members reinforced with fibre reinforced polymer (FRP) bars," Composite Structures, vol. 56, no. 1, pp. 63-71, 2002.

[9] T. H. Almusallam, "Analytical prediction of flexural behavior of concrete beams reinforced by FRP bars," Journal of Composite Materials, vol. 31, no. 7, pp. 640-657, 1997.

[10] R. Masmoudi, M. Theriault, and B. Benmokrane, "Flexural behavior of concrete beams reinforced with deformed fiber reinforced plastic reinforcing rods," ACI Structural Journal, vol. 95, no. 6, pp. 665-676, 1998.

[11] Y. F. Wu, "Ductility demand of compression yielding fiberreinforced polymer-reinforced concrete beams," ACI Structural Journal, vol. 105, no. 1, pp. 104-110, 2008.

[12] S.-B. Kang, K. H. Tan, and E.-H. Yang, "Progressive collapse resistance of precast beam-column sub-assemblages with engineered cementitious composites," Engineering Structures, vol. 98, pp. 186-200, 2015.

[13] N. Krstulovic-Opara, K. A. Watson, and J. M. Lafave, "Effect of increased tensile strength and toughness on reinforcing-bar bond behavior," Cement and Concrete Composites, vol. 16, no. 2, pp. 129-141, 1994.

[14] D. Lau and H. J. Pam, "Experimental study of hybrid FRP reinforced concrete beams," Engineering Structures, vol. 32, no. 12 , pp. 3857-3865, 2010.

[15] E. Dehghani, F. Daneshjoo, A. A. Aghakouchak, and N. Khaji, "A new bond-slip model for adhesive in CFRP-steel composite systems," Engineering Structures, vol. 34, no. 1, pp. 447-454, 2012.

[16] W. Ge, J. Zhang, D. Cao, and Y. Tu, "Flexural behaviors of hybrid concrete beams reinforced with BFRP bars and steel bars," Construction and Building Materials, vol. 87, pp. 28-37, 2015.

[17] Y. Zhou, H. Fu, P. Li, D. Zhao, L. Sui, and L. Li, "Bond behavior between steel bar and engineered cementitious composite (ECC) considering lateral FRP confinement: test and modeling," Composite Structures, vol. 226, Article ID 11206, 2019.

[18] D. Zhao, W. Yi, and S. K. Kunnath, "Shear mechanisms in reinforced concrete beams under impact loading," Journal of Structural Engineering, ASCE, vol. 143, no. 9, Article ID 04017089, 2017.
[19] L. Bertolini, F. Bolzoni, P. Pedeferri, L. Lazzari, and T. Pastore, "Cathodic protection and cathodic preventionin concrete: principles and applications," Journal of Applied Electrochemistry, vol. 28, no. 12, pp. 1321-1331, 1998.

[20] P. Pedeferri, "Cathodic protection and cathodic prevention," Construction and Building Materials, vol. 10, no. 5, pp. 391402, 1996.

[21] R. B. Polder, G. Leegwater, D. Worm, and W. Courage, "Service life and life cycle cost modelling of cathodic protection systems for concrete structures," Cement and Concrete Composites, vol. 47, no. 47, pp. 69-74, 2014.

[22] R. B. Polder and W. H. A. Peelen, "Service life aspects of cathodic protection of concrete structures," in Concrete Repair. A practical guide, CRC Press, Boca Raton, FL, USA, 2011.

[23] F. Lee-Orantes, A. A. Torres-Acosta, M. Martínez-Madrid, and C. lópez-cajún, "cathodic protection in reinforced concrete elements, using carbon fibers base composites," ECS Transactions, vol. 3, no. 3, pp. 198-201, 2007.

[24] S. Gadve, A. Mukherjee, and S. N. Malhotra, "Corrosion protection of fiber-reinforced polymer-wrapped reinforced concrete," ACI Materials Journal, vol. 107, no. 4, pp. 349-356, 2010.

[25] P. Lambert, C. Van Nguyen, P. S. Mangat, F. J. O’Flaherty, and G. Jones, "Dual function carbon fibre fabric strengthening and impressed current cathodic protection (ICCP) anode for reinforced concrete structures," Materials and Structures, vol. 48, no. 7, pp. 2157-2167, 2015.

[26] C. Van Nguyen, P. Lambert, P. S. Mangat, F. J. O’Flaherty, and G. Jones, "Near-surface mounted carbon fibre rod used for combined strengthening and cathodic protection for reinforced concrete structures," Structure \& Infrastructure Engineering, vol. 12, no. 3, pp. 1-10, 2015.

[27] Ministry of Housing and Urban-Rural Development of the People's Republic of China, Standard Methods for Testing of Concrete Structures, Ministry of Housing and Urban-Rural Development of the People's Republic of China, Beiijng, China, 1992.

[28] NACE SP0290-2007, Impressed Current Cathodic Protection of Reinforcing Steel in Atmospherically Exposed Concrete Structures, NACE International, Houston, TX, USA, 2007.

[29] M. Stern and A. L. Geaby, "Electrochemical polarization," Journal of the Electrochemical Society, vol. 104, no. 1, pp. 56-63, 1957.

[30] J. A. den Uijl and A. J. Bigaj, "A bond model for ribbed bars based on concrete confinement," Heron, vol. 41, no. 3, pp. 201-226, 1996. 